\title{
Massive gastric pneumatosis from pyloric stenosis
}

\author{
Rodrick K. Lim BSc MD, Scott McKillop MD, Paul J. Karanicolas MD PhD, Leslie Scott MD
}

Previously published at www.cmaj.ca

A 12-week-old infant presented with a one-day history of increased vomiting and lethargy. Gastroesophageal reflux had been diagnosed when he was four weeks old, but the symptoms had not lessened, despite a change of formula. The infant was severely dehydrated and had gastric distension, a decreased level of consciousness and gasping respirations. There was no abdominal tenderness. He was resuscitated with tracheal intubation and intravenous fluids. A plain radiograph showed massive gastric pneumatosis (Figure 1). Blood test results showed hypochloremic metabolic alkalosis. Ultrasonography suggested hypertrophic pyloric stenosis. The patient was stabilized, and a nasogastric tube was inserted for decompression. At the time of pyloromyotomy five days after admission, he had a markedly hypertrophied pylorus, and pneumatosis was still palpable in the stomach wall. The infant was discharged home in good condition four days after surgery.

Fraenkel first described the unusual presentation of air within the wall of the stomach in 1889.' The condition can be noninfectious (gastric pneumatosis) or infectious (emphysematous gastritis). The mortality rate for gastric pneumatosis is $41 \%$ in adults and $6 \%$ in children. ${ }^{2}$

Gastric pneumatosis is caused by a disruption of the gastric mucosa, which results in air dissecting into the stomach wall. This disruption typically results from gastric outlet obstruction caused by pyloric stenosis (as in this case), duodenal stenosis ${ }^{3}$ or tumours; it can also result from protracted vomiting, instrumentation or tracking of air through the mediastinum or the pneumothorax. Pyloric stenosis is the most common cause of intestinal obstruction in infants.

Emphysematous gastritis refers to mucosal disruption caused by gas-forming bacterial invasion. An antecedent gastric mucosal injury may allow infiltration of the bacteria. Causes in infants include necrotizing enterocolitis, caustic ingestion, recent abdominal surgery or gastroenteritis. ${ }^{4}$ These patients present with fever, appear unwell and have laboratory evidence of leukocytosis.

\section{This article has been peer reviewed.}

From the Department of Pediatrics (Lim, McKillop, Scott), the Department of Radiology (McKillop) and the Department of Surgery (Karanicolas, Scott), Children's Hospital, London Health Sciences Centre, Schulich School of Medicine \& Dentistry, University of Western Ontario, London, Ont.

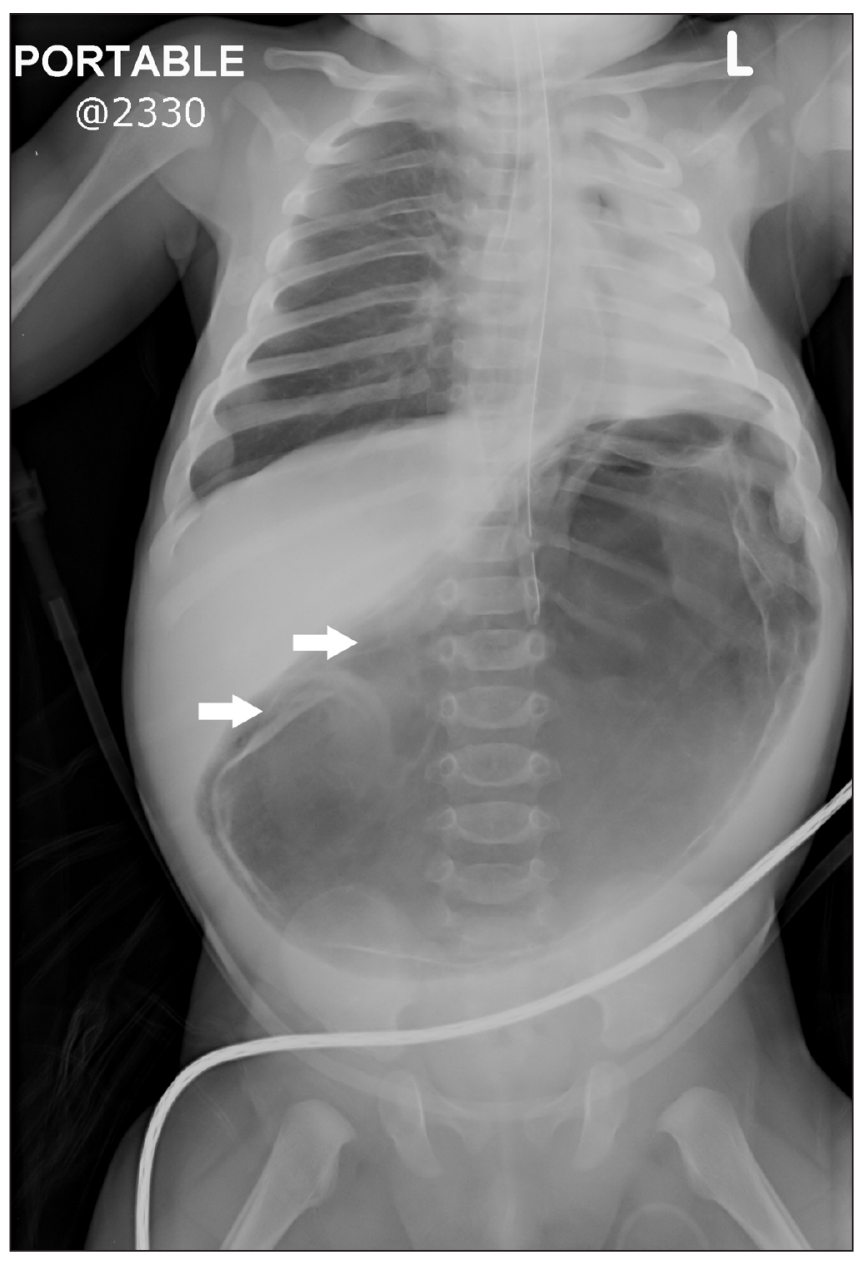

Figure 1: A plain radiograph of the abdomen of a 12-week-old infant showing massive gastric pneumatosis within walls of stomach (arrows).

Competing interests: None declared.

\section{REFERENCE}

1. Fraenkel E. Uber einen fall von gastritis acuta emphysematosa wahrscheinlich mykotischen ursprungs. Virchows Arch Pathol Anat 1889:118;526-35.

2. Taylor D, Tung J, Baffa J, et al. Gastric pneumatosis: a case report and review of the literature. Int Pediatr 2000;15:117-20.

3. D'Cruz R, Emile S. Gastroduodenal emphysema. J Pediatr Surg 2008;43:2121-3.

4. Moosvi AR, Saravolatz LD, Wong HD, et al. Emphysematous gastritis: case report and review. Rev Infect Dis 1990;12:848-55. 